\title{
Genetic characteristics in four farmed tilapia (Oreochromis niloticus) populations evaluated by microsatellite markers
}

\author{
Ha T. T. Tran ${ }^{1 *}$, Trang T. Vu ${ }^{1}$, Nam P. Nguyen ${ }^{2}$, Giang T. H. Luu ${ }^{1}$, \\ Nhat H. Pham ${ }^{1}$, \& Diep H. Nguyen ${ }^{1}$ \\ ${ }^{1}$ Research Institute for Aquaculture No. 1, Bac Ninh, Vietnam \\ ${ }^{2}$ Faculty of Biotechnology, Vietnam National University of Agriculture, Ha Noi, Vietnam
}

\begin{abstract}
ARTICLE INFO
Research Paper

Received: May 16, 2019

Revised: October 03, 2019

Accepted: October 07, 2019
\end{abstract}

Keywords

Genetic diversity

Microsatellite

Nile tilapia

\section{${ }^{*}$ Corresponding author}

Trần Thị Thúy Hà

Email: thuyha@ria1.org

\section{ABSTRACT}

In this study, genetic characteristics of four tilapia strains including NOVIT4, $13^{\text {th }}$ GIFT generation, China and Philippine were investigated by analysis the genotype at 6 microsatellite loci. It was found that all loci showed high polymorphism with 51 identified alleles, in which GM139 and UNH995 loci were the highest polymorphism with the appearance of 14 and 11 alleles, respectively. Deficiency of expected heterozygosity occurred in all tilapia strains, the Ho value of which was lower than the He one. Besides, 17/24 loci was significantly different from the Hardy-Weinberg principle $(P<0,05)$. The Fst ranging from 0.012 to 0.025 indicated that the genetic difference among populations was small. However, the analysis of molecular variance (AMOVA) showed that the genetic diversity at the molecular level among individuals within the same population and among individuals were high, corresponding to $36.69 \%$ and $61 \%$, respectively. The findings of this study are useful in term of giving the genetic information of four Nile tilapia strains for the selective breeding program.

Cited as: Tran, H. T. T., Vu, T. T., Nguyen, N. P., Luu, G. T. H., Pham, N. H., \& Nguyen, D. H. (2019). Genetic characteristics in four farmed tilapia (Oreochromis niloticus) populations evaluated by microsatellite markers. The Journal of Agriculture and Development 18(5), 52-61. 


\title{
Đặc điểm di truyền một số quần đàn cá rô phi vằn (Oreochromis niloticus) qua phân tích chỉ thi microsatellite
}

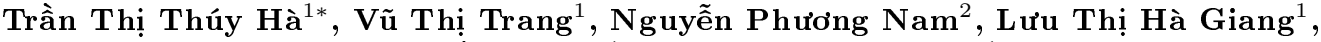 \\ Phạm Hồng Nhật ${ }^{1}$ \& Nguyễn Hồng Điệp ${ }^{1}$ \\ ${ }^{1}$ Viện Nghiên Cứu Nuôi Trồng Thủy Sản I, Bắc Ninh \\ ${ }^{2}$ Khoa Công Nghệ Sinh Học, Học Viện Nông Nghiệp Việt Nam, Hà Nội
}

\section{THÔNG TIN BÀI BÁO \\ Bài báo khoa học \\ Ngày nhận: 16/05/2019 \\ Ngày chỉnh sửa: 03/10/2019 \\ Ngày chấp nhận: 07/10/2019}

Từ khóa

Cá rô phi vằn

Đa dạng di truyền

Microsatellite

*Tác giả liên hệ

Trần Thị Thúy Hà

Email: thuyha@ria1.org

\section{TÓM TẮT}

Đặc điểm di truyền của cá rô phi vằn các dòng NOVIT4, GIFT thế hệ thứ 13, Trung Quốc và Philippine đã được tìm hiểu trong nghiên cứu này qua phân tích kiểu gen tại 06 vị trí microsatellite. Tất cả các vị trí nghiên cứu đều thể hiện tính đa hình cao với 51 alen được xác định, trong đó locus GM139 và UNH995 có tính đa hình alen cao nhất với sự xuất hiện tương ứng 14 và 11 alen. Hiện tượng thiếu hụt dị hợp tử mong đợi xuất hiện ở các dòng cá rô phi nghiên cứu với giá trị Ho thấp hơn He. Di truyền của $17 / 24$ vị trí microsatellite ở bốn dòng cá sai khác có ý nghĩa so với định luật Hardy-Weinberg $(P<0,05)$. Giá trị Fst dao động từ 0,012 đến 0,025 thể hiện sự sai khác di truyền nhỏ giữa các dòng nghiên cứu. Tuy nhiên, kết quả phân tích biến đổi phân tử (AMOVA) thể hiện đa dạng di truyền ở mức độ phân tử giữa các cá thể trong cùng một dòng và giữa các cá thể với nhau là cao, lần lượt dạt $36,69 \%$ và $61 \%$. Kết quả nghiên cứu này cung cấp các thông tin di truyền của các dòng cá rô phi vằn phục vụ các nghiên cứu về lựa chọn các quần đàn cá bố mẹ thích hợp khi đưa vào chương trình chọn giống tiếp theo.

\section{1. Đặt Vấn Đề}

Cá rô phi là đối tượng thủy sản nước ngọt quan trọng trên thế giới và ở Việt Nam. Chọn giống cá rô phi đã thực hiện từ rất sớm, như chọn giống cá rô phi sinh trưởng nhanh, chịu lạnh, và màu sắc. Thông thường, trước khi thực hiện chương trình chọn giống, tìm hiểu đặc điểm di truyền của các quần đàn ban đầu là cần thiết và sẽ góp phần phục vụ công tác lai tạo có hiệu quả.

Cho đến nay, đã có không ít nghiên cứu sử dụng chỉ thị microsatellite trong đánh giá đa dạng di truyền trên cá rô phi. Hassanien \& Gilbey (2005) nghiên cứu đa dạng di truyền của 5 quần đàn cá rô phi vằn (Oreochromis niloticus) qua phân tích kiểu gen của 6 chỉ thị microsatellite. Kết quả cho thấy các chỉ thị này rất hữu hiệu trong đánh giá đa dạng và ứng dụng trong chọn lọc các tính trạng chọn giống mong muốn. Bên cạnh đó, Boris \& ctv. (2011) đã sử dụng 5 microsatellite (UNH106, UNH222, UNH172, UNH123 và UNH216) nghiên cứu đặc điểm di truyền của cá rô phi đen $(O$. mossambicus) và đã chọn lọc được các đàn cá vật liệu ban đầu cho chọn giống.

Ở Việt Nam, việc phân tích đa dạng di truyền sử dụng chỉ thị microsatellite dã được thực hiện trên một số đàn cá rô phi. Nghiên cứu sử dụng 04 chỉ thị microsatellite đánh giá 16 tổ hợp lại từ 4 dòng cá rô phi vằn (dòng Thái Lan, Đài Loan, Israel và dòng cá chọn giống NOVIT-4), đã lựa chọn 5/16 tổ hợp lai để hình thành vật liệu ban đầu phục vụ chọn giống cá rô phi (Tran \& ctv., 2013). Bên cạnh đó, Nguyen \& ctv. (2014) đã sử dụng ba dòng cá rô phi GIFT, Đài Loan và NOVIT4 làm vật liệu ban đầu để chọn giống cá có khả năng chịu mặn (15 - 20 ppt). Sau bốn thế hệ chọn lọc, giá trị chọn giống cho tính trạng trọng lượng tăng dao động từ 1,1 - 1,6.

Trong các nghiên cứu trên, chỉ thị phân tử microsallite được sử dụng nhiều do có tính ưu việt (Liu \& Cordes, 2004). Microsatellite có tính đa hình rất cao, là marker đồng trội và tuân theo 
định luật Mendel. Vì vậy, hiệu quả và độ chính xác của những phép tính di truyền quần thể dựa trên chỉ thị này so với một số chỉ thị phân tử khác được tăng lên. Vị trí của microsatellite có thể dễ dàng xác định bằng $\mathrm{PCR}$ từ một lượng $\mathrm{DNA}$ rất nhỏ. Ở cá, một microsatellite được tìm thấy trên mỗi 1,87 kb của DNA. Bên cạnh đó, với số lần lặp lớn $(\geq 10)$, trình tự lặp lại thường đơn giản (2 - 4 nucleotide), microsatellite đã và đang được sử dụng nhiều trong nuôi trồng thủy sản (Deepak \& ctv., 2017).

Nghiên cứu này đánh giá đa dạng di truyền 4 dòng cá rô phi vằn dựa trên 6 chỉ thị microsatellite theo các nghiên cứu của Hassanien \& Gilbey (2005) và Boris \& ctv. (2011). Kết quả nghiên cứu sẽ là cơ sở cho việc hình thành quần đàn ban đầu phục vụ công tác chọn giống.

\section{Vật Liệu và Phương Pháp Nghiên Cứu}

\subsection{Vật liệu nghiên cứu}

Mẫu cá rô phi vằn được thu từ 4 quần đàn cá rô phi có nguồn gốc khác nhau, đang được nuôi giữ tại Trung tâm chọn giống cá rô phi Quảng Nam, thuộc Viện Nghiên cứu Nuôi trồng Thủy sản I (Viện NCNT Thủy sản I), bao gồm: Cá rô phi vằn dòng NOVIT-4 thế hệ thứ 12; Cá rô phi vằn chọn giống dòng GIFT thế hệ thứ 13; Cá rô phi vằn chọn giống sinh trưởng nhanh dòng Trung Quốc và dòng Philippine.

\subsection{Phương pháp nghiên cứu}

\subsubsection{Thu mẫu}

Mẫu vây ngực được thu từ 4 quần đàn cá rô phi (30 cá thể/quần đàn), bảo quản trong cồn $98 \%$ và vận chuyển về phòng thí nghiệm Sinh học phân tử, Trung tâm Công nghệ sinh học Thủy sản, Viện Nghiên Cứu Nuôi Trồng Thủy Sản I. Mẫu được giữ ở $4^{0} \mathrm{C}$ cho đến khi phân tích.

\subsubsection{Tách chiết DNA}

DNA tổng số được tách chiết theo phương pháp của Sambrook \& Russell (2001). DNA tổng số được kiểm tra định tính bằng cách điện di trên thạch agarose 0,8\% trong dung dịch đệm TBE $1 \times$, dưới hiệu điện thế $120 \mathrm{~V}, 60 \mathrm{~mA}, 30$ phút. Nồng độ và độ tinh sạch của DNA tổng số được xác định bằng máy Nanodrop 2000C. Lượng DNA mỗi lần đo là $1 \mu \mathrm{L}$. DNA được coi là sạch protein và RNA nếu có các chỉ số như sau: $\mathrm{OD}_{260 / 280}=$ $1,8-2,0 ; \mathrm{OD}_{260 / 230}=1,8-2,2$.

\subsubsection{Tối ưu phản ứng $\mathrm{PCR}$}

Lựa chọn chỉ thị microsatellite: Trong nghiên cứu này, chúng tôi lựa chọn 6 chỉ thị microsatellite: UNH136, UNH104, UNH203, UNH103, UNH995, GM139 (Bảng 1). Các chỉ thị được lựa chọn dựa vào kết quả của các nghiên cứu trước đây, tính đa hình của các chỉ thị và không có sự sai khác với quy luật di truyền Hardy-Weinberg.

Tối ưu phản ứng PCR: Phản ứng PCR được tối ưu dựa vào quy trình của bộ kit $2 \times$ Master mix (Thermo Scientific). Thành phần phản ứng trong thể tích $25 \mu \mathrm{L}$ gồm: $1 \mu \mathrm{L}(50-100 \mathrm{ng})$ DNA khuôn; $5 \mu \mathrm{L}$ PCR Master; $1 \mu \mathrm{L}$ mồi $10 \times$ mỗi loại và $17 \mu \mathrm{L}$ dd $\mathrm{H}_{2} \mathrm{O}$ khử trùng. Phản ứng được tiến hành trên máy PCR Mastercycler proS (Eppendorf) với các điều kiện của phản ứng như sau: biến tính sợi khuôn ở $94^{0} \mathrm{C}$ trong 5 phút; 35 chu kỳ $\left(94^{0} \mathrm{C}\right.$ trong 30 giây, Ta $\left({ }^{0} \mathrm{C}\right)$ trong 45 giây, $72^{\circ} \mathrm{C}$ trong 1 phút); $72^{0} \mathrm{C}$ trong 10 phút và giữ ở $4^{0} \mathrm{C}$. Tuy nhiên, các điều kiện trên sẽ được điều chỉnh tối ưu để phù hợp với nhiệt độ gắn mồi của từng mồi cụ thể phụ thuộc vào đặc tính của mồi và được trích dẫn ở Bảng 1 .

\subsubsection{Phản ứng phân tích đoạn}

Phân tích đoạn được thực hiện trên hệ thống phân tích di truyền đa năng GenomeLab GeXP (Beckman Coulter). Sản phẩm PCR được pha loãng theo tỷ lệ $1 \mu \mathrm{L}$ sản phẩm $\mathrm{PCR}$ với $3 \mu \mathrm{L}$ nước tinh khiết. Chuẩn bị dung dịch hỗn hợp cho 8 mẫu phân tích đoạn bao gồm: $240 \mu \mathrm{L}$ SLS (Solution Loading Sample) và $2 \mu \mathrm{L}$ Size Standard 600, trộn đều. Sau đó lây $29 \mu \mathrm{L}$ dung dịch hỗn hợp vào mỗi giếng trên đĩa mẫu. Thêm $1 \mu l$ sản phẩm PCR đã được pha loãng vào mỗi giếng, trộn đều. Thêm 1 giọt dầu lên trên mỗi giếng chứa mẫu.

\subsubsection{Phân tích số liệu}

Mẫu sau khi chạy xong được ghi nhận alen bằng phần mềm GeneMarker V.2.2.0. Các thông số di truyền (tần số alen, số alen ở mỗi vị trí microsatllite, Ho, He, Fis và $\mathrm{HWE}$ test) được phân tích bằng phần mềm GenAlex 6.5 (Peakall \& Smouse, 2006). Mức độ đa hình của các locus microasatellite (PIC) được tính dựa trên Website online: PIC caculator. Nghiên cứu biến dị di 


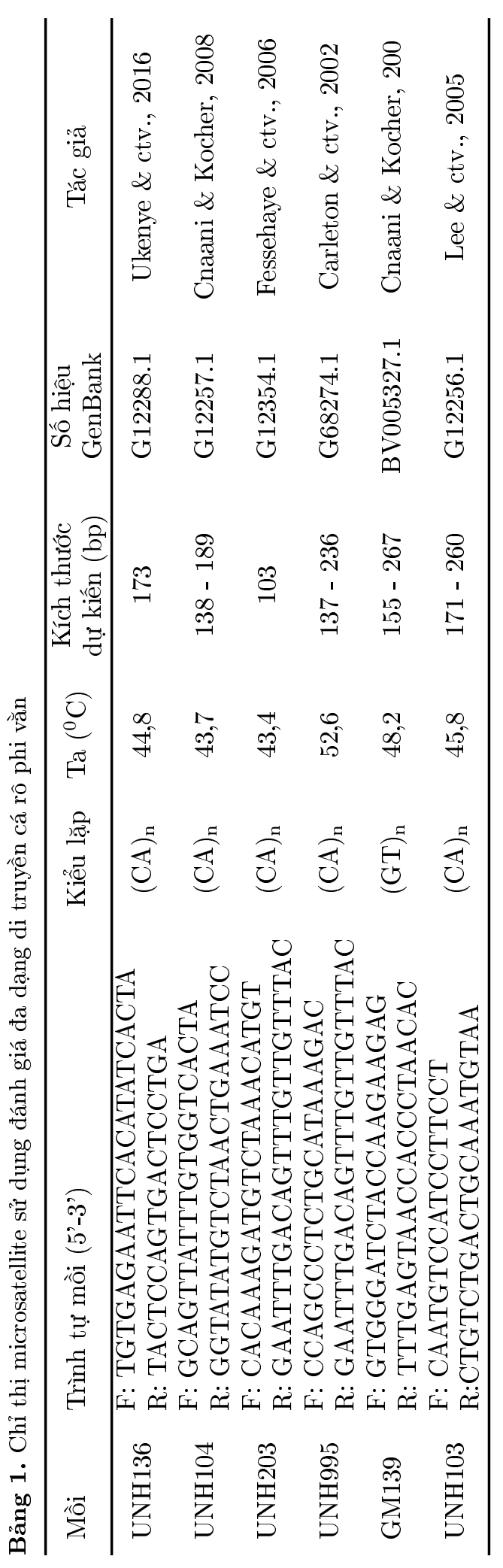

truyền qua chỉ số FST và khoảng cách di truyền của các quần đàn được kiểm định bằng phân tích AMOVA trên phần mềm Arlequin 3.1 (Excoffier \& ctv., 1992).

\section{Kết Quả và Thảo Luận}

\subsection{Kết quả DNA tổng số}

Kết quả kiểm tra định lượng DNA (Hình 1) cho thấy các mẫu DNA tổng số có nồng độ dao động trong khoảng $60 \mathrm{ng} / \mu \mathrm{L}$ dến $3.108 \mathrm{ng} / \mu \mathrm{L}$. Nồng độ DNA khác nhau là do chất lượng và lượng mẫu đầu vào khác nhau. Tỷ lệ OD260/280 và $\mathrm{OD} 260 / 230$ của tất cả các mẫu đều dao động trong khoảng cho phép là 1,8 đến 2,2 ; chứng tỏ DNA không lẫn tạp protein và RNA. Kết quả điện di (Hình 2) đều cho các băng DNA sáng rõ, đảm bảo tốt cho phản ứng khuếch đại DNA (PCR).

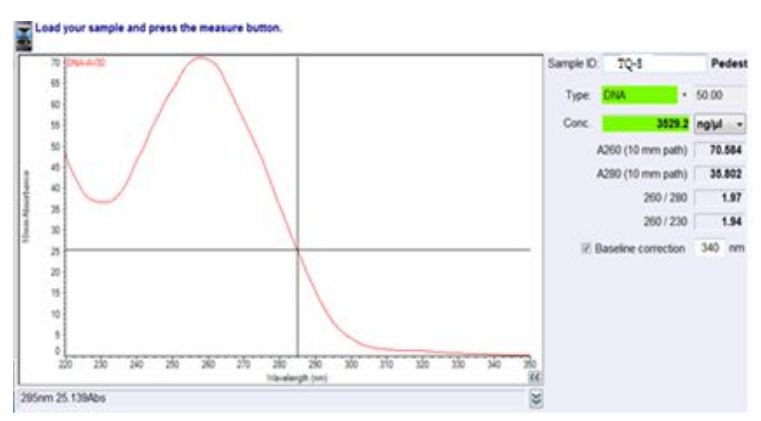

Hình 1. Kết quả định lượng và kiểm tra độ tinh sạch của DNA tổng số mẫu TQ-5 (Trung Quốc-5).

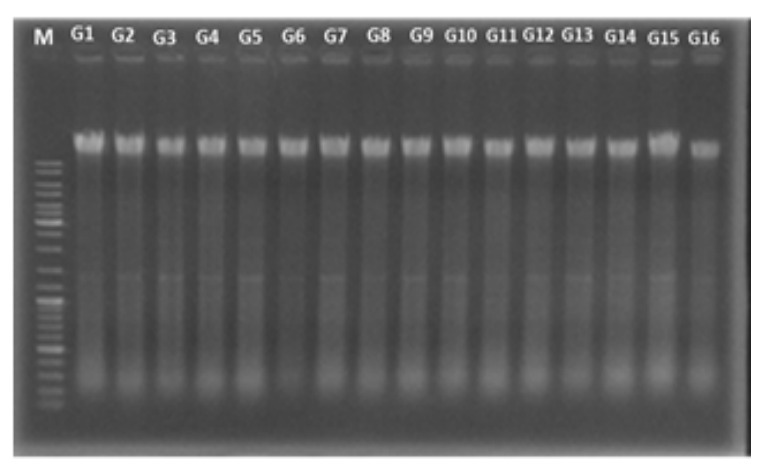

Hình 2. Kết quả điện di DNA tổng số mẫu cá rô phi dòng GIFT trên gel agarose $0,8 \%$.

M: ladder $1 \mathrm{~kb}, \mathrm{G} 1$ dến G16 là DNA tổng số của cá rô phi dòng GIFT mẫu số 1 đến mẫu số 16 . 


\subsection{Tối ưu phản ứng $\mathrm{PCR}$}

Kết quả tối ưu PCR cho thấy 6 mồi cho băng vạch sáng, rõ nét và không có sản phẩm phụ. Sản phẩm $\mathrm{PCR}$ có kích thước nằm trong khoảng 100-300 bp và phù hợp với kích thước dự kiến trong các nghiên cứu trước đây của Kocher \& ctv. (1998); Pham \& Quyen (2008); Nguyen \& Luu (2013). Theo đó sản phẩm PCR mồi GM139 và các mồi UNH104, UNH103, UNH995, UNH136, UNH203 kích thước nằm trong khoảng như được trình bày ở Bảng 1 và minh họa ở Hình 3 và 4 .

\section{MI $111213141516 \quad 1718$}

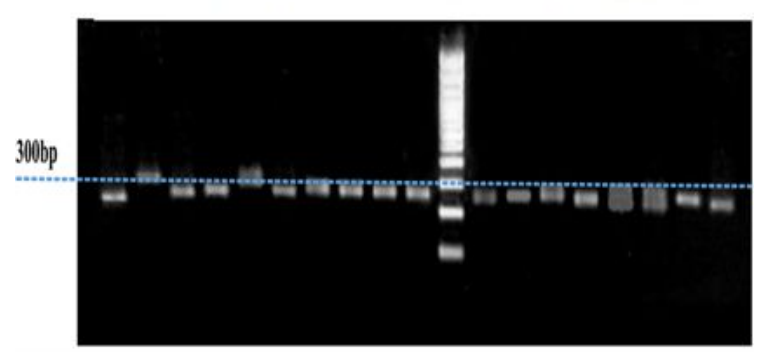

Hình 3. Hình ảnh điện di sản phẩm PCR khuếch đại bằng chỉ thị GM139 trên gel agarose $2 \%$.

Giếng 1-10: sản phẩm PCR dòng GIFT; Giếng 11 18: sản phẩm PCR dòng Trung Quốc; M: ladder 100 bp

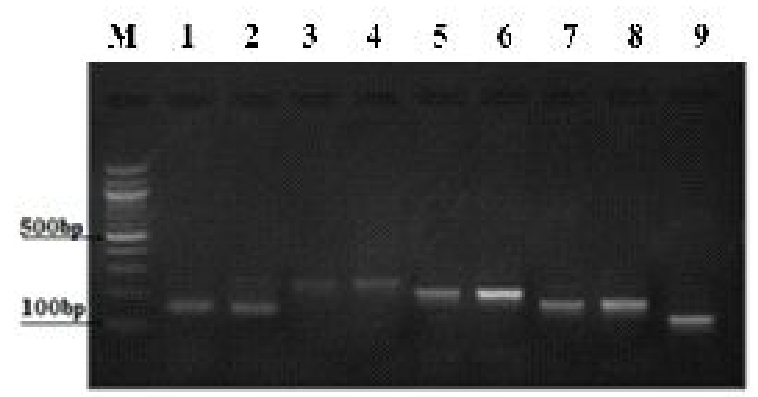

Hình 4. Kết quả điện di sản phẩm $\mathrm{PCR}$ với mồi huỳnh quang trên gel agarose $2 \%$.

Giếng M: ladder 100 bp; Giếng 1,2: sản phẩm PCR mồi UNH 104; Giếng 3,4: sản phẩm PCR mồi UNH 103; Giếng 5,6: sản phẩm PCR mồi UNH 995; Giếng 7,8: sản phẩm PCR mồi UNH 136; Giếng 9: sản phẩm PCR mồi UNH 203.

\subsection{Kết quả phân tích đoạn trên hệ thống GenomeLab GeXP}

Nghiên cứu đã xác định được kích thước các alen của từng vị trí microsatellite mẫu phân tích và được biểu thị bằng hình ảnh tín hiệu đồ. Hình ảnh tín hiệu đồ rõ nét và không nhiễu. Đối với các cá thể đồng hợp sẽ quan sát được duy nhất 1 đỉnh tín hiệu đồ. Ngược lại, với các cá thể dị hợp sẽ quan sát được 2 đỉnh của tín hiệu đồ riêng rẽ tương ứng với 2 alen tách biệt (Hình 5).

\section{4. Đa dạng di truyền của các quần đàn cá rô phi vằn}

3.4.1. Đa hình các locus microsatellite (SSR)

- Tần số alen và độ đa dạng của alen

Kết quả 6 locus microsatellite (Bảng 2) trong nghiên cứu đều thể hiện tính đa hình cao với tổng cộng 51 alen được xác định, kích thước dao động từ 100 - 300 bp. Trong đó, 2 locus GM139 và UNH995 có tính đa hình alen cao nhất với sự xuất hiện tương ứng 14 alen và 11 alen; ít nhất là 3 alen tại locus UNH136. Nhìn chung, số lượng alen của từng locus SSR là nhiều hơn so với các nghiên cứu trước đây trên cá rô phi ở trong nước. Cụ thể, số alen tại locus UNH104 trong nghiên cứu của Pham \& Quyen (2008) là 3 alen, trong nghiên cứu của Nguyen \& Luu (2013) là 4 alen trên cá rô phi vằn.

Bên cạnh các alen xuất hiện với tần số cao, có một số alen hiếm, xuất hiện với tần số thấp. Cụ thể, tại locus UNH995, alen 172; alen 160 và alen 186 chỉ xuất hiện tương ứng ở quần đàn NOVIT-4, Trung Quốc và Philippin. Sự khác biệt này có thể do trong các chương trình chọn giống; như chọn giống sinh trưởng, chịu lạnh trên dòng NOVIT-4; chọn giống sinh trưởng nhanh trên dòng Philippin và Trung Quốc đã xuất hiện những alen mới khác biệt với các quần đàn chọn giống ban đầu thể hiện sự thích nghi với điều kiện môi trường. Bên cạnh đó, có thể do quá trình đột biến, tái tổ hợp, trôi dạt di truyền và chọn lọc tự nhiên. Với tần số xuất hiện rất thấp trong quần đàn, các alen này có thể dễ dàng mất đi nếu không có sự lai tạo để duy trì hoặc cũng có thể tạo ưu thế lai cho thế hệ sau nếu tiếp tục chọn lọc. Sự xuất hiện của các alen có tần số thấp ở tất cả các locus phân tích cũng xuất hiện trong nghiên cứu của Bui \& ctv. (2011).

- Mức độ đa hình của mỗi locus, PIC

Chỉ số PIC thường được sử dụng trong di truyền học như một thước đo tính đa hình của các chỉ thị (Shete \& ctv., 2000). Theo Botstein \& ctv. (1980), PIC là chỉ số về mức độ biến đổi di truyền; PIC > 0,5 được coi là có mức độ đa hình cao; 0,25 


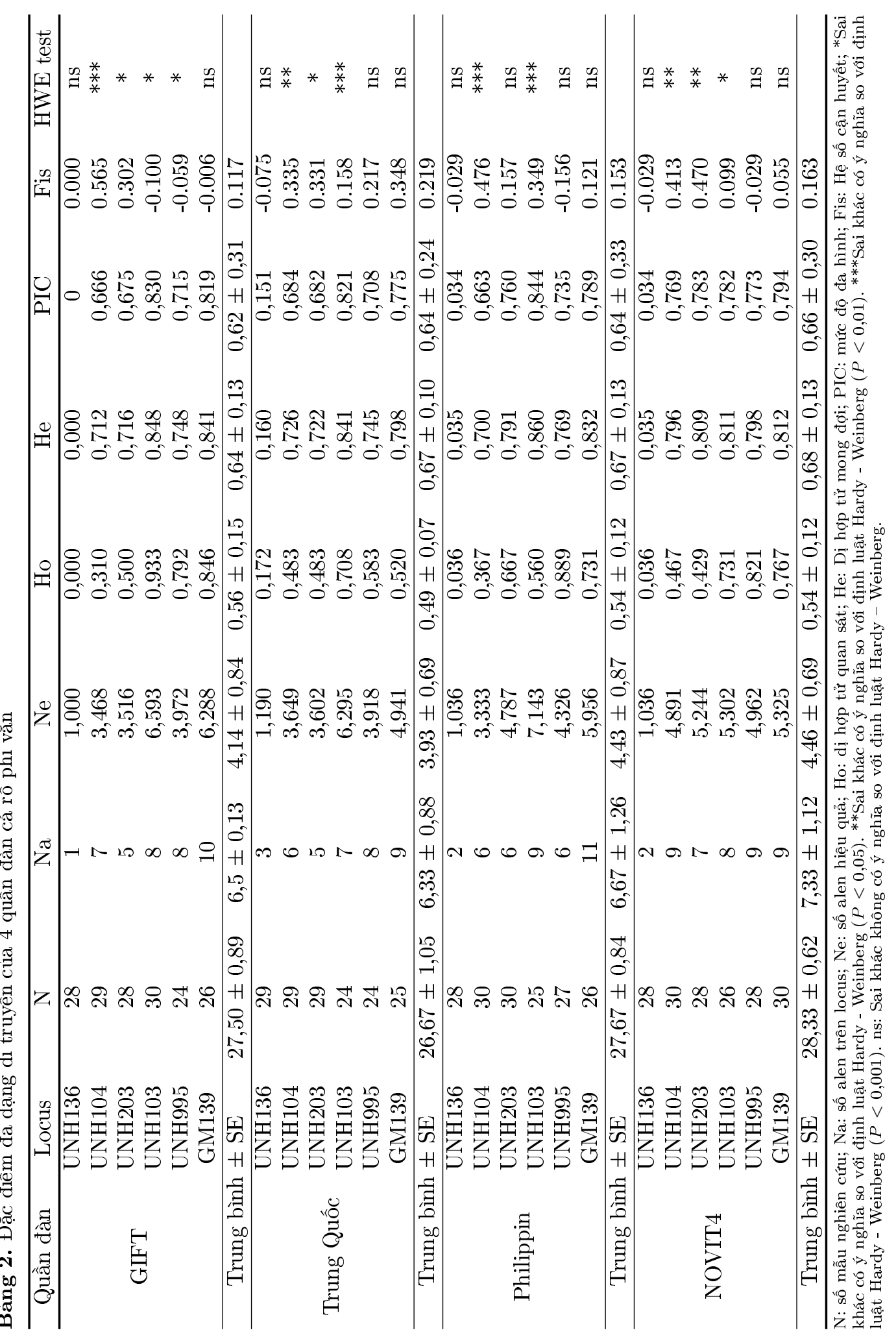



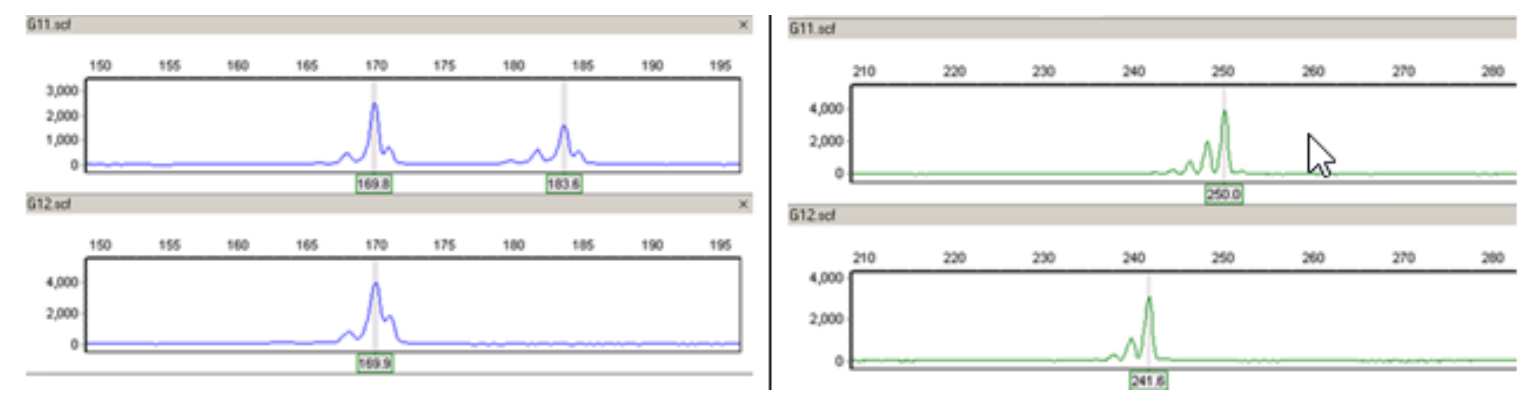

Hình 5. Kết quả phân tích đoạn locus UNH995 (trái) và locus GM139 (phải) trên hai mẫu cá rô phi dòng GIFT (G11 và G12)

$<\mathrm{PIC}<0,5$ là có mức độ đa hình trung bình; và $\mathrm{PIC}<0,25$ là mức độ đa hình nhỏ. Trong nghiên cứu này, chỉ số PIC dao động trong khoảng 0,6 0,8 ; trung bình là 0,$68 ; 5$ locus có mức độ đa hình cao và chỉ duy nhất locus UNH136 có mức độ đa hình nhỏ (dao động từ 0 - 0,1); có thể do locus này có mức độ đa dạng alen thấp (chỉ có một đến ba alen trong quần đàn). Do đó, 5 locus UNH103, UNH104, UNH203, UNH995 và GM139 phù hợp để sử dụng trong đánh giá đặc điểm đa dạng di truyền quần thể và xác định sự khác biệt về di truyền. Sun \& ctv. (2015) đã nghiên cứu trên tổng số 120 chỉ thị SSRs, phát hiện 18 locus có tính đa hình cao (giá trị PIC trung bình là 0,5 ) được chọn để thử nghiệm tương quan với khả năng sinh trưởng ở một loài cá biển (Mandarin fish). Trong nghiên cứu đánh giá đa dạng các quần đàn cá rô phi tại tỉnh Quảng Châu, Trung Quốc đã sử dụng 10 locus microsatallite, trong đó 8 locus microsatallite có mức độ đa hình locus cao và 02 locus có mức độ đa hình locus vừa phải và cả 10 locus này đều được chọn để đánh giá đa dạng di truyền các quần đàn rô phi, trong đó có locus UNH995 (Gu \& ctv., 2014).

\subsection{2. Đa dạng di truyền của quần thể}

- Tính dị hợp tử

Bảng 2 cho thấy, tất cả các locus ở 4 dòng cá rô phi đều có sự thiếu hụt dị hợp tử mong đợi, giá trị dị hợp tử quan sát (Ho) thấp hơn giá trị dị hợp tử mong đợi $(\mathrm{He})$. Cụ thể, giá trị Ho trung bình của dòng GIFT, Trung Quốc, Philippine và NOVIT-4 lần lượt là 0,$56 ; 0,49 ; 0,54 ; 0,54$ tương ứng với giá trị He trung bình là 0,$64 ; 0,67 ; 0,67 ; 0,68$. Sự thiếu hụt dị hợp tử thường xuyên được đề cập trong các nghiên cứu trên đối tượng thủy sản qua phân tích kiểu gen bằng chỉ thị microsatellite (Launey \& ctv., 2001). Điều này có thể giải thích do giao phối cận huyết trong các chương trình chọn giống, nên xuất hiện các alen lặn. Sự xuất hiện của các alen "câm" hay lỗi trong phản ứng khuếch đại cũng có thể là nguyên nhân (Cruz \& ctv., 2004). Các giá trị Ho và $\mathrm{He}$ trong nghiên cứu này tương đương so với nghiên cứu của Pham \& Quyen (2008) khi xem xét sự biến đổi di truyền của các quần đàn cá rô phi vằn dòng GIFT, Đài Loan và Viện 1 sử dụng 4 cặp mồi UNH216; UNH104; UNH124 và IGF - MS03 (giá trị Ho, He dao động tương ứng $0,64-0,69 ; 0,56-0,83)$.

- Hệ số cận huyết

Lai cận huyết là việc sinh ra con từ việc lai tạo của các cá thể hoặc sinh vật có quan hệ gần gũi về mặt di truyền. Hệ số cận huyết (Fis) là xác suất để hai alen ở bất kỳ locus nào giống hệt nhau do có nguồn gốc từ một tổ tiên chung. Giá trị Fis dao động từ 0 đến 1 . Fis bằng 0 có nghĩa quần thể đang ở trạng thái cân bằng HardyWeinberg hay nói cách khác là quần thể không có giao phối hay lai cận huyết. Fis $<0$ trong trường hợp có quá nhiều dị hợp tử quan sát được $(\mathrm{Ho})$ (Wright, 1950; Kincaid, 1983). Trong nghiên cứu này, giá trị Fis trung bình từ 6 locus của 4 dòng cá rô phi nhìn chung là thấp, có nghĩa là mức độ cận huyết thấp. Các giá trị Fis lần lượt là 0.117 (dòng GIFT); 0.153 (dòng Philippin); 0.163 (dòng NOVIT4) và 0.219 (dòng Trung Quốc) (Bảng 3 ).

\section{- Cân bằng Hardy-Weinberg (HW)}

Di truyền của $17 / 24$ microsatellite trên các dòng cá nghiên cứu sai khác có ý nghĩa so với định luật cân bằng HW $(P<0,05)$ (Bảng 2). Trong đó, di truyền của 3 locus UNH995 và GM139 và UNH136 đều lệch khỏi cân bằng HW ở cả bốn dòng cá nghiên cứu. Sự cân bằng $\mathrm{HW}$ trong quần đàn có ý nghĩa rất quan trọng trong xác định 
Bảng 3. Hệ số sai khác di truyền $\left(\mathrm{F}_{\mathrm{ST}}\right)$ giữa các dòng cá rô phi vằn

\begin{tabular}{ccccc}
\hline GIFT & Trung Quốc & Philippine & NOVIT 4 & \\
\hline 0,000 & & & & GIFT \\
0,025 & 0,000 & & & Trung Quốc \\
0,018 & 0,012 & 0,000 & & Philippine \\
0,016 & 0,018 & 0,016 & 0,000 & NOVIT 4 \\
\hline
\end{tabular}

Bảng 4. Kết quả phân tích phương sai phân tử (AMOVA) của các quần đàn nghiên cứu dựa trên dữ liệu của 6 locus microsatellite

\begin{tabular}{lcccc}
\hline Nguồn biến động & Độ tự do & $\begin{array}{c}\text { Tổng bình } \\
\text { phương }\end{array}$ & $\begin{array}{c}\text { Thành phần } \\
\text { biến động }\end{array}$ & $\begin{array}{c}\text { Phần trăm } \\
\text { biến động }\end{array}$ \\
\hline Giữa các quần đàn & 3 & 6,042 & $0,01704 \mathrm{~V}^{\mathrm{a}}$ & 2,31 \\
Giữa các cá thể trong một quần đàn & 116 & 115,00 & $0,27069 \mathrm{~V}_{\mathrm{b}}$ & 36,69 \\
Giữa các cá thể & 120 & 54,000 & $0,45000 \mathrm{~V}_{\mathrm{c}}$ & 61,00 \\
Tổng & 239 & 175,042 & 0,73773 & \\
\hline
\end{tabular}

tần số alen lặn, tần số của các "thể mang" và trong đánh giá di truyền thế hệ sau của quần đàn. Theo Nei (1978), lạc dòng di truyền, giao phối cận huyết, cách ly địa lý có thể là một trong những nguyên nhân dẫn đến không cân bằng di truyền của một quần đàn. Trong nghiên cứu này, locus UNH136 có mức độ đa hình các alen thấp, mức độ dị hợp tử thấp có thể là nguyên nhân làm mất cân bằng HW. Ở 2 locus UNH995 và GM 139 đều xuất hiện những alen có tần số rất thấp. Những alen này có thể dễ dàng mất đi nếu không có cách thức duy trì và quản lý tốt. Việc lai tạo giữa các dòng cá rô phi có nguồn gốc khác nhau là một giải pháp hữu hiệu giúp duy trì đa dạng alen và có thể phục hồi một phần sự đa dạng di truyền mất đi cũng như hạn chế mức độ cận huyết như đề xuất của Freitas \& ctv. (2007) và Zou \& ctv. (2015). Tình trạng mất cân bằng HW của các dòng cá rô phi chọn giống cũng được đề cập trong nghiên cứu của Bui \& ctv. (2011) trên cá rô phi đỏ, với tất cả các dòng trên tất cả các locus nghiên cứu đều lệch khỏi định luật $\mathrm{HW}$.

- Quan hệ di truyền và hệ số sai khác di truyền $\left(\mathrm{F}_{\mathrm{ST}}\right)$

Sự khác biệt về di truyền các quần thể thường được đánh giá dựa trên khoảng cách di truyền giữa chúng (Nei, 1987; Laval \& Claude, 2002) và hệ số sai khác di truyền $\mathrm{F}_{\mathrm{ST}}$ của Wright (1969). Theo Nei (1972) nếu giá trị $\mathrm{F}_{\mathrm{ST}}<0,05$ được cho là sai khác di truyền nhỏ; $0,05<\mathrm{F}_{\mathrm{ST}}<0,15$ được cho là sai khác di truyền trung bình và $\mathrm{F}_{\mathrm{ST}}>0,15$ được cho là sai khác di truyền rõ rệt.

Bảng 3 cho thấy giá trị $\mathrm{F}_{\mathrm{ST}}$ dao động từ 0,012 đến 0,025 ; không có sự sai khác di truyền lớn giữa các quần đàn nghiên cứu. Quần đàn Trung Quốc và Philippin có quan hệ di truyền gần gũi hơn so với các quần đàn còn lại. Kết quả báo cáo của Bui \& ctv. (2011) sử dụng 6 microsatellite (OM02; OM05; UNH216; UNH231; UNH159; UNH172) cũng cho thấy giá trị $\mathrm{F}_{\mathrm{ST}}$ không có sự khác biệt di truyền có ý nghĩa giữa bốn dòng cá rô phi trong nghiên cứu. Theo Freitas \& Galetti (2005) và Refstie \& Gjedrem (2005) nhân giống dựa vào kiểu hình và giao phối cận huyết đã góp phần thúc đẩy đáng kể tạo nên sự tương đồng di truyền giữa các quần thể.

AMOVA là một phương pháp để phát hiện mức độ khác biệt di truyền giữa các quần thể khác nhau sử dụng các chỉ thị phân tử (Excoffier \& ctv., 1992). Kết quả phân tích AMOVA (Bảng 4) cho thấy, đa dạng di truyền mức độ phân tử cao giữa các cá thể trong cùng một quần đàn $(36,69 \%)$ và giữa các cá thể với nhau $(61,00 \%)$. Mức độ đa dạng giữa 4 quần thể cá rô phi vằn tương đối thấp $(2,31 \%)$. Điều này cho thấy không có cấu trúc quần thể rõ ràng ở 4 quần đàn nghiên cứu và hầu như không có sự biến đổi di truyền trên các locus được khảo sát. Kết quả của nghiên cứu này tương đồng với kết quả của Eguia \& ctv. (2004) và Boris \& ctv. (2011) trên quần thể cá rô phi vằn và cá rô phi đỏ chọn giống có khác biệt di truyền thấp.

Qua đánh giá mức độ khác biệt di truyền giữa các quần thể và các cá thể, việc lai chéo giữa các cá thể khác nhau trong cùng hoặc khác quần thể là một giải pháp tối ưu nâng cao đa dạng di truyền và hạn chế tác động tiêu cực của cận huyết cũng như nâng cao ưu thế lai, những đặc tính tốt (sinh trưởng, chịu lạnh) của các dòng cá rô phi 
vằn trong nghiên cứu.

\section{Kết Luận}

Trong nghiên cứu này 5 locus (UNH103, UNH104, UNH203, UNH995 và GM139) có tính đa hình cao với tổng số alen là 7-14 alen, mức độ đa hình các locus cao (chỉ số PIC trung bình là 0,6). Một số alen hiếm xuất hiện tần số thấp ở dòng cá NOVIT-4, Trung Quốc và Philippin. Sự sai khác di truyền của 4 quần đàn cá rô phi không rõ rệt, hệ số sai khác di truyền nhỏ. Bốn dòng cá rô phi đều có sự thiếu hụt dị hợp tử ở tất cả các locus do giá trị dị hợp tử quan sát $(\mathrm{Ho})$ nhỏ hơn giá trị dị hợp tử mong đợi $(\mathrm{He})$. Kết quả phân tích AMOVA thể hiện đa dạng di truyền ở mức độ phân tử giữa các cá thể trong cùng một quần đàn và giữa các cá thể với nhau là cao. Như vậy, 4 quần đàn cá rô phi vằn sử dụng trong nghiên cứu này đều có tính đa dạng di truyền ở mức độ trung bình và chênh lệch không đáng kể. Kết quả này là cơ sở khoa học về di truyền phục vụ các nghiên cứu về chọn dòng cá bố mẹ thích hợp trong chương trình chọn giống.

\section{Lời Cám Ơn}

Nghiên cứu này được thực hiện dưới sự hỗ trợ kinh phí từ đề tài cấp Bộ "Nghiên cứu chọn giống nâng cao tốc độ tăng trưởng của cá rô phi vằn Oreochromis niloticus" - Bộ Nông nghiệp và Phát triển Nông thôn. Nhóm tác giả xin chân thành cảm ơn Trung tâm chọn giống cá rô phi Quảng Nam đã hỗ trợ thu mẫu cá để chúng tôi hoàn thành nghiên cứu này.

\section{Tài Liệu Tham Khảo (References)}

Boris, B. R., Xenia, C. O., \& Marcela, S. V. (2011). Genetic diversity of six populations of red hybrid tilapia, using microsatellites genetic markers. Revista $M V Z$ Córdoba 16(2), 2491-2498.

Botstein, D., White, R. L., Skolnick, M., \& Davis, R. W. (1980). Construction of a genetic linkage map in man using restriction fragment length polymorphisms. American Journal of Human Genetics 32(3), 314-331.

Bui, T. L. H., Le, C., Nguyen, D., \& Trinh, Q. T. (2011). Genetic diversity of Red Tilapia (Oreochromis spp) by microsatellite. Collection of 35 years of Research Institute for Aquaculture No.2. Ha Noi, Vietnam: Agricultural Publishing House.

Carleton, K. L., Streelman, J. T., Lee, B. Y., Garnhart, N., Kidd, M., \& Kocher, T. D. (2002). Rapid isolation of CA microsatellites from the tilapia genome. Animal Genetics 33(2), 140-144.
Cnaani, A., \& Kocher, T. D. (2008). Sex-linked markers and microsatellite locus duplication in the cichlid species Oreochromis tanganicae. Biology letters 4(6), 700-703.

Cruz, A. M., Mills, K., Rodriguez, F., Schoua, C., Yurrita, M. M., Molina, E., Palmieri, M., \& Black, W. C. (2004). Gene flow among Anopheles albimanus populations in Central America, South America, and the Caribbean assessed by microsatellites and mitochondrial DNA. The American Journal of Tropical Medicine and Hygiene 71(3), 350-359.

Deepak, J., Ram, R. N., \& Pushpa. (2017). Microsatellite markers and their application in fisheries International Journal of Advances in Agricultural Science and Technology 4 (10), 67-104.

Eguia, M. R., Ikeda, M., U Basiao, Z., \& Taniguchi, N. (2004). Genetic diversity in farmed Asian Nile and red hybrid tilapia stocks evaluated fro microsatellite and mitochondrial DNA analysis. Aquaculture 236(1),131150 .

Excoffier, L. E., Smouse, P., \& Quattro, J. (1992). Analysis of molecular variance inferred from metric distances among DNA haplotypes: Application to human mitochondrial DNA restriction Data. Genetics 131(2), 479491.

Fessehaye, Y., Elbialy, Z., Rezk, M. A., Crooijmans, R. P., Bovenhuis, H., \& Komen, H. (2006). Mating systems and male reproductive success in Nile Tilapia (Oreochromis niloticus) in breeding hapas: A microsatellite analysis. Aquaculture 256(1),148-158.

Freitas, P. D., \& Galetti, P. M. (2005). Assessment of the genetic di-versity in five generations of a commercial broodstock line of Litopenaeus vannamei shrimp. African Journal of Biotechnology 4, 1362-1367.

Freitas, P. D., Calgaro, M. R., \& Galetti Jr, P. M. (2007). Genetic diversity within and between broodstocks of the white shrimp Litopenaeus vannamei (Boone, 1931) (Decapoda, Penaeidae) and its implication for the gene pool conservation. Brazilian Journal of Biology 67(4), 939-943.

Gu, D., Mu, X., Song, H., Luo, D., Xu, M., Luo, J., \& Hu, Y. C. (2014). Genetic diversity of invasive Oreochromis spp. (tilapia) populations in Guangdong province of China using microsatellite markers. Biochemical Systematics and Ecology 55, 198-204.

Hassanien, H. A., \& Gilbey, J. (2005). Genetic diversity and differentiation of Nile tilapia (Oreochromis niloticus) revealed by DNA microsatellites. Aquaculture Research 36(14), 1450-1457.

Kincaid, H. L. (1983). Inbreeding in fish populations used for aquaculture. Aquaculture 33(1), 215-227.

Kocher, T. D., Lee, W. J., Sobolewska, H., Penman, D., \& McAndrew, B. (1998). A genetic linkage map of a cichlid fish, the tilapia (Oreochromis niloticus). Genetics 148(3), 1225-1232. 
Launey, S., Barre, M., Gerard, A., \& Naciri-Graven, Y. (2001). Population bottleneck and effective size in Bonamia ostrea-resistant populations of Ostrea edulis as inferred by microsatellite markers. Genet Res 78(3), 259-270.

Laval, G., \& Claude, C. (2002). Measuring genetic distances between breeds: Use of some distances in various short term evolution models. Genetics Selection Evolution 34(4), 481-507.

Lee, B. Y., Lee, W. J., Streelman, J. T., Carleton, K. L., Howe, A. E., Hulata, G., Slettan, A., Stern, J. E., Terai, Y., \& Kocher, T. D. (2005). A second-generation genetic linkage map of tilapia (Oreochromis spp.). Genetics $170(1)$, 237-244.

Liu, Z. J., \& Cordes, J. F. (2004). DNA marker technologies and their applications in aquaculture genetics. Aquaculture 238(1), 1-37.

Nei, M. (1987). Molecular Evolutionary Genetics. New York, USA: Columbia University Press.

Nei, M. (1978). Estimation of average heterozygosity and genetic distance from a small number of individuals. Genetic 89(3), 585-590.

Nei, M. (1972). Genetic distance between population. American Naturalist 106, 283-292.

Nguyen, H. N., \& Luu, T. H. G. (2013). Genetic study of microsatellite markers on hybrid tilapia producing all male fish. Journal of Agriculture and Rural Development 2, 71-76.

Nguyen, H. N., Ngo, P. T., Knibb, W., \& Nguyen, H. N. (2014). Selection for enhanced growth performance of Nile tilapia (Oreochromis niloticus) in brackish water (15-20ppt) in Vietnam. Aquaculture 428-429, 1-6.

Peakall, R. \& Smouse P. E. (2006). GENALEX 6: genetic analysis in Excel. Population genetic software for teaching and research. Molecular Ecology Notes 6(1), 288-295.

Pham, T. A., \& Quyen, T. D. (2008). Comparison of microsatellite polymorphism on Prl-1 promoter gene and growth in tilapia (Oreochromis niloticus) cultured in salt water. Journal of Science and Development $\mathrm{VI}(4), 348-352$.
Refstie, T., \& Gjedrem, T. (2005) Reproductive traits in aquatic animals. In: Gjedrem T. (Ed.) Selection and breeding programs in aquaculture. Dordrecht, Netherlands: Springer.

Sambrook, J., \& Russell, D. (2001). Molecular cloning: A laboratory manual. New York, USA: Cold Spring Harbor Laboratory Press.

Shete, S., Tiwari, H., \& Elston, R. C. (2000). On estimating the heterozygosity and polymorphism information content value. Theoretical Population Biology 57(3), 265-271.

Sun, L., Li, J., Liang, X., Yi, T., Fang, L., Sun, J., \& Yang, M. (2015). Microsatellite DNA markers and their correlation with growth traits in mandarin fish (Siniperca chuatsi). Genetics and Molecular Research 14(4), 19128-19135.

Tran, H. T. T., Vu, T. T., Nguyen, T. H., \& Nguyen, H. N. (2013). Assessment of genetic characteristics for tilapia combinations (Oreochromis niloticus) by microsatellite markers. National Biotechnology Conference (854-858). Ha Noi, Vietnam.

Ukenye, E. A., Taiwo, I. A., Oguntade, O. R., Oketoki, T. O., \& Usman, A. B. (2016). Molecular characterization and genetic diversity assessment of Tilapia guineensis from some coastal rivers in Nigeria. African Journal of Biotechnology 15(1), 20-28.

Wright, S. (1969). Evolution and the genetics of populations, volume 2: The theory of gene frequencies. University of Chicago Press.

Wright, S. (1950). Genetic structure of populations. British Medical Journal 2(4669), 36-36.

Zou, Z., Li, D., Zhu, J., Han, J., Xiao, W., Yang, H. (2015). Genetic variation among four bred populations of two tilapia strains, based on mitochondrial D-loop sequences. Mitochondrial DNA 26(3), 426-430. 